\title{
Evaluation of the BDNF, NGF, NT3 and NT4 Genes Expressions in the Brains of Neonatal Mice with Hypothyroidism
}

\author{
Hamid Reza Adeli Bhroz ${ }^{1}$, Kazem parivar ${ }^{2}$, Iraj Amiri ${ }^{3}$ \& Nasim Hayati Roodbari ${ }^{4}$ \\ ${ }^{1}$ Department of Biology, Science and Research Branch, Islamic Azad University, Tehran, Iran \\ ${ }^{2}$ Department of Biology, Science and Research Branch, Islamic Azad University, Tehran, Iran \\ ${ }^{3}$ Anatomy and Embryology Department, Medical School, Hamadan University of Medical Science, Hamadan, Iran \\ ${ }^{4}$ Department of Biology, Science and Research Branch, Islamic Azad University, Tehran, Iran \\ Correspondence: Kazem Parivar. Department of Biology, Science and Research Branch, Islamic Azad University, \\ Tehran, Iran. Email: kazem_parivar@yahoo.com
}

Received: July 22, 2017

doi:10.5539/jmbr.v7n1p171
Accepted: August 5, 2017

Online Published: November 10, 2017

URL: https://doi.org/10.5539/jmbr.v7n1p171

\begin{abstract}
Background and Aim: Thyroid is one of the endocrine glands, (T3 and T4) play a significant role in the development of prenatal brain and the following stages. The study aimed to evaluate the effect of hypothyroidism on the amount of expression of NT4, NT3, nerve growth factor (NGF) and brain-derived neurotrophic factor (BDNF) in brain of one-day rat neonates with hypothyroidism.

Materials and Methods: In total, 25 mature mice of Albino NMRI race were selected after mating, divided into three group, control, as well as low-dose and high-dose intervention groups. Samples of the control group received pure water during pregnancy, whereas subjects of the intervention group with low and high doses of the medication were administered with $20 \mathrm{mg}$ and $100 \mathrm{mg}$ methimazole powder (dissolved in $100 \mathrm{cc}$ water), respectively. After child delivery, blood samples were obtained from mother mice to determine the level of T3 and T4 in blood serum. Following that, the brain of one-day mice were removed by surgery and assessed to determine the amount of expression of NT4, NT3, NGF and BDNF using the complete kit of RT-PCR.
\end{abstract}

Results: Levels of T4 and T3 in the control group were $28 \mathrm{ug} / \mathrm{dl}$ and $1.59 \mathrm{ug} / \mathrm{dl}$, respectively. In the low-dose intervention group, the amounts of the mentioned hormones were $8 \mathrm{ug} / \mathrm{dl}$ and $0.85 \mathrm{ug} / \mathrm{dl}$, significantly, indicating a significant reduction in the expression of NT4, NT3, NGF and BDNF genes, compared to the control group. Moreover, $\mathrm{T} 4$ and T3 were $6 \mathrm{ug} / \mathrm{dl}$ and $0.79 \mathrm{ug} / \mathrm{dl}$ in the high-dose group, respectively, conveying a significant decrease in the expression of NT4, NT3, NGF and BDNF genes, compared to the control group $(\mathrm{P}<0.05)$.

Keywords: BDNF, NGF, Hypothyroidism, NT3

\section{Introduction}

Thyroid is one of the major endocrine glands, hormones of which include triiodothyronine (T3) and thyroxine T4 (Wagner et al., 2008). These hormones play a major role in regulation of basal metabolism, as well as brain growth and development in utero and in the following stages of life. There have been no justifiable reports on synthesis of thyroid hormones in central nervous system (CNS) cells. In fact, the only resource for thyroid hormones for fetus before the activation of its own thyroid gland is maternal thyroid gland.The maternal-fetal thyroid interactions decreases after the activation of fetal thyroid gland in the 16th day (Pérez-Castillo et al., 1985). Thyroid hormones are necessary for development of brain functions, such as neurogenesis, neuronal migration, differentiation of neurons and glial cells, myelination and synapse formation. Activities of thyroid hormone are mainly related to T3 involvement with core receptors, regulating gene expressions. In other words, expression of the majority of genes is directly or indirectly regulated by thyroid hormone (Navarro et al., 2014). All maternal-fetal thyroid interactions are made by Oatplc 1 and MTC 8 carriers, which are highly expressed throughout the nervous system and can pass the blood-brain barrier (Muller \& Heuer, 2014). A part of T3 thyroid hormone in brain is obtained from general circulation, whereas the majority of the mentioned hormones are observed with T4 in astrocytes. Studies have shown that $\mathrm{T} 3$ thyroid hormones cause the release of brain-derived neurotrophic factor (BDNF) and nerve growth factor (NGF) neurotrophic factors through affecting astrocytes. The neurotrophic factor of BDNF plays an important role in neural guidance, transcription of certain genes and exiting the heterochromatic mode (Gilbert \& 
Lasley, 2013). Therefore, the major effects of thyroid hormones are on neuron differentiation through affecting the development and separation of glial cells, especially astrocytes. In response to the impact of thyroid hormones, astrocytes differentiate some of the growth factors and secrete ECM components, providing an appropriate platform for neurons (Ringstedt et al., 1998). According to the literature, Methyl MercaptoImidazole (MMI) is a suitable medication for treatment of hypothyroidism through inhibiting the synthesis of thyroid hormones in thyroid gland (Cooper, 2005). On the other hand, neurotrophins (NTs) are one of the protein familiesy, regulating the growth, maintenance and apoptosis of neurons during their development, as well as damages to the neurons (Ceni, 2014). These components in mammals comprise NGF, BDNF, NT4, NT3, which was then called NT5 (Skaper, 2012). Given the notes mentioned above, the aim of our study is to evaluate the expression of BDNF, NGF, NT3 and NT4 genes in the brains of neonatal mice with hypothyroidism.

\section{Materials and Methods}

The research was conducted on 25 white female albino NMRI mice weighing 30 gr provided by Pasteur Institute of Iran. Each five mice were kept in a cage in controlled conditions (e.g., temperature and light) with access to special food and in the special animal room for one week before the experiment. Prepared for fertility, the female mice were mated with male mice. After the confirmation of pregnancy and formation of vaginal plaque, samples were randomly divided into three groups of control (pure water), low-dose intervention (low dose of medication) and high-dose intervention (high dose of medication) from the second half of the fourth day.The control group received pure water during the pregnancy period, whereas the low-dose and high-dose intervention groups were administered with $20 \mathrm{mg}$ and $100 \mathrm{mg}$ of methimazole powder (provided by "Shimi Daroo Co."), completely dissolved in $100 \mathrm{mg}$ of drinking water, respectively. During the pregnancy period, a suitable and controlled condition was provided for mice.

\section{1- Sampling and Measurement of T3 and T4}

After delivery, mother mice were anesthetized with ether and dissected. Blood samples were obtained from inferior vena cava using syringe. After centrifuge and preparation of hematocrit of T3 and T4 amounts, serum was measured and analyzed using ELISA kits (manufactured by Padtan Gostar Isar Co.).

\section{2- Dissection of brains of one-day neonate mice}

After complete disconnection of head of the animals from their bodies, special sterile scissors were used to cut the upper part of the heads. With minimum amount of damage to brain tissues, the upper part of the skull was removed. In order to prevent the interference of results, new sterile sets of surgical tools were used for each animal. The whole brain was removed from the skull and immediately transferred to liquid nitrogen and kept in $-80^{\circ} \mathrm{C}$ until performing the additional tests.

3- Brain Preparation for Evaluation of NT4, NT3, NGF and BDNF Gene Expression and PGK1 Gene was selected as the reference gen

The amount of gene expression was relatively measured, using the following procedure: first, the frozen brain tissue was taken out and turned into powder using liquid nitrogen. The obtained powder was put in $2 \mathrm{ml}$ micro tubes and applied to perform the RT-PCR process (Realp-Pce2x Master Mix Kit-Ampliqon, Denmark). In addition, specific primers were designed applying oligo7 software, followed by their synthesis in "Gen Fanavaran Co.". Table 1 shows Properties of used primers in Real-time PCR reaction in the next stage, Ct value was analyzed using $2^{-\Delta \Delta C}$ Levick model, followed by the assessment of gene expression with respect to the normal group.

Table 1. Properties of used primers in Real-time PCR reaction

\begin{tabular}{lll}
\hline Gene name & Accession number & Primer sequences \\
\hline PKG1 & NM_008828 & F GGCATTCTGCACGCTTCAAA \\
& & R AAGTCCACCCTCATCACGAC \\
NGF & NM_013609 & F AGCTTTCTATACTGGCCGCAG \\
& & R AGGGCTGTGTCAAGGGAATG \\
BDNF & NM_007540 & F CTTTGCGGATATTGCGAAGGG \\
& & R CTGGTGGAACATTGTGGCTTTG \\
NT3 & NM_008742 & F AGTCCACCTTTCTCTTCATGTCG \\
& & R CTCCTTTGATCCATGCTGTTGC \\
NT4 & NM_198190 & F CAGCCGGGGAGCAGAGAA \\
& & R ACACCTGTCAACAGCAGCAC
\end{tabular}

Data analysis was performed using one-way analysis of variance and Tukey's test and the values expressed Mean \pm SEM. In addition, P-value of less than 0.05 was considered statistically significant. 


\section{Results}

\section{1- T3 and T4}

Evaluation of blood serum of mice in the control group revealed that the amounts of T4 and T3 were 27 and 1.85 $\mathrm{ug} / \mathrm{dl}$, respectively. The mentioned hormones were 8 and $0.85 \mathrm{ug} / \mathrm{dl}$ in blood serum of samples of the low-dose intervention group, respectively, indicating a significant reduction, compared to the control group $(\mathrm{P}<0.05)$. In the high-dose intervention group, the amounts of T4 and T3 were reported to be 6 and $0.75 \mathrm{ug} / \mathrm{dl}$, respectively, revealing a significant difference, compared to the control group $(\mathrm{P}<0.05)$.

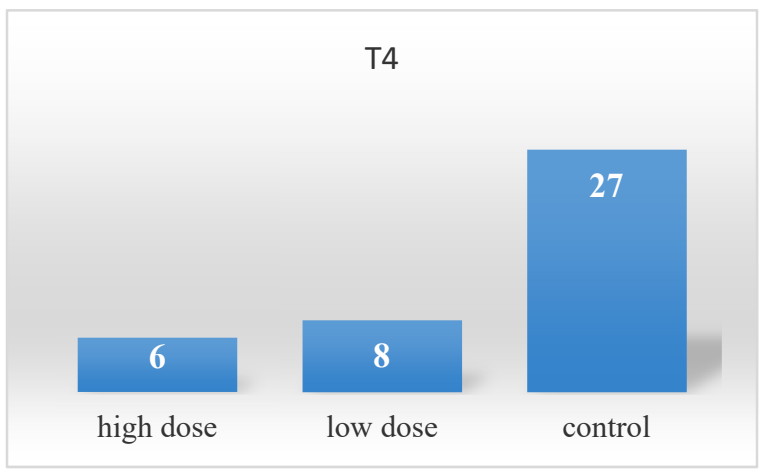

Figure 1. Effect of methimazole on concentration of blood thyroxine $(\mathrm{n}=8)$

Significant difference with the control group $(\mathrm{P}<0.05)$, no significant difference between the lowdose and high-dose intervention groups

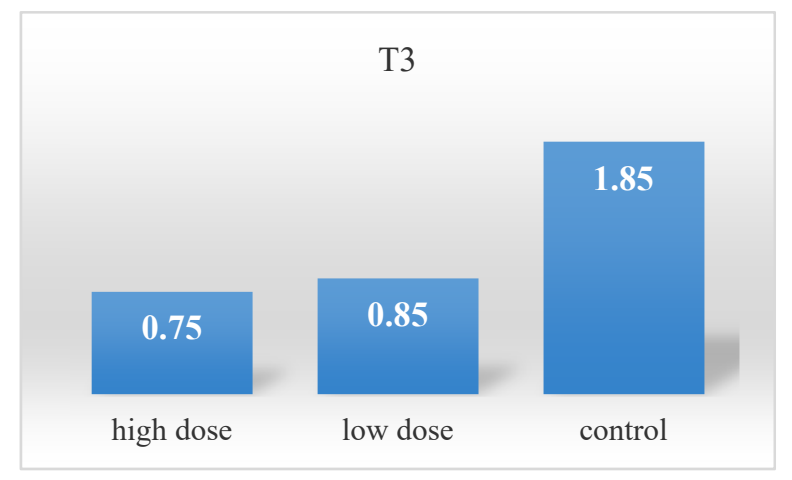

Figure 2. Effect of methimazole on concentration of blood triiodothyronine $(\mathrm{n}=8)$

Significant difference with the control group $(\mathrm{P}<0.05)$, no significant difference between the lowdose and high-dose intervention groups

2- Results of Relative Evaluation of NT4, NT3, NGF and BDNF Gene Expression After the assessment of the amount of expression of these genes using RT-PCR, it was demonstrated that expression of BDNF gene significantly more decreased in low-dose intervention group, compared to the control group (more than 50\%). Similarly, significant reduction was observed in the high-dose intervention group, compared to the control group. Similar results were obtained for NGF and NT3 genes.

In addition, reduced expression of NT4 was about 0.1 and 0.06 in the low-dose and high-dose intervention groups, respectively $(\mathrm{P}<0.05)$.

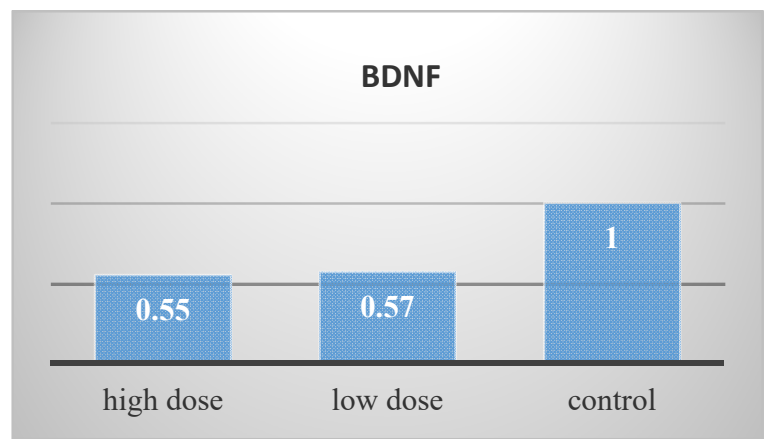

Figure 3. Effect of methimazole on relative expression of BDNF $(\mathrm{n}=8)$

Significant difference with the control group $(\mathrm{P}<0.05)$

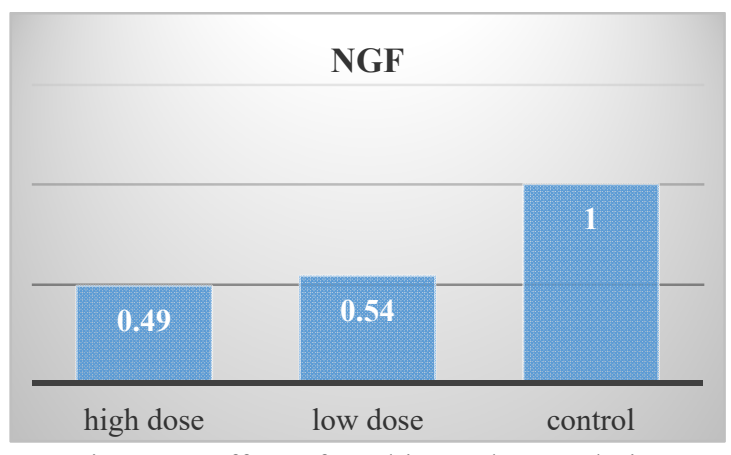

Figure 4. Effect of methimazole on relative expression of NGF $(\mathrm{n}=8)$

Significant difference with the control group $(\mathrm{P}<0.05)$ 


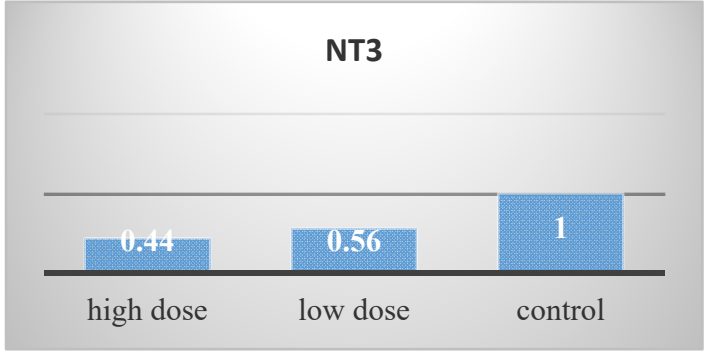

Figure 5. Effect of methimazole on relative expression of NT3 $(n=8)$

Significant difference with the control group $(\mathrm{P}<0.05)$

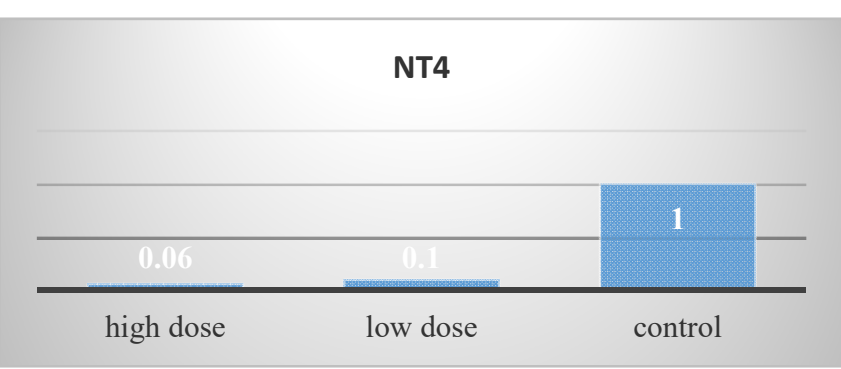

Figure 6. Effect of methimazole on relative expression of NT4 $(n=8)$

Significant difference with the control group $(\mathrm{P}<0.05)$

\section{Discussion and Conclusion}

Thyroid hormones play a major role in early events of brain development, such as migration and differentiation of neuronal terminals in neurons and glial cells. Thyroid hormones are extremely important for neural migration in cortex, hippocampus and cerebellum. Moreover, thyroid hormone is involved in the early phases of cellular migration from external germinal layer to internal germinal layer, causing delay in the migration of granular cells (Fauquier, 2014).

Studies have indicated that hypothyroidism leads to delay in creation and weakening of myelin (Balazs, 1969). Thyroid hormones have an important role in differentiation of oligodendrocytes and cause defects in axonal maturation (Gravel, 1990). Evaluation of culture of fetal neurons revealed that thyroid hormones play a role in regulation of gene expression in fetal brain in utero (Sinha, 2008).

In the cerebral cortex, thyroid hormones control the genes involved in cytoskeleton biogenesis, neural migration and growth and neuropathy sprouting (Navarro et al., 2014). Furthermore, thyroid hormones control the expression of many genes that code proteins differentiated at cellular terminals, including cell cycle regulators, cytoskeletal proteins, neurotrophins and their receptors and extracellular matrix proteins (Wood, 2002).

Some impacts of thyroid hormones in differentiation and survival are controlled through the expression of neurotrophins. Reaction between thyroid hormones and NGF for growth and maintenance of cholinergic neurons in the anterior base of the brain is of paramount importance (Gould \& Butcher, 1989). Changes in NGF and P75 were reported after hypothyroidism (Alvarez-Dolado, 1994). In cerebellum, thyroid hormones control the expression of NT3. In culture of cerebral granular cells, thyroid hormones control the differentiation of Purkinje cells by intermediating of NT3, created in granular cells (Lindholm et al, 1993).

In the present study, it was demonstrated that female pregnant mice with induced hypothyroidism by Methimazole, gene expression of BDNF significantly decreased in neonatal brain, compared to the control group. In addition, expression of NGF and NT3 and NT4 neurotrophins significantly reduced, compared to the control group. In conclusion, both low-dose and high-dose intervention groups experienced higher levels of reduction in NT4 (0.1 and 0.06 , respectively), compared to the control group. It could be suggested that thyroid hormones play a role in the expression of the mentioned gene, and any reduction in these hormones could reduce gene expression in brain of infant mice with hypothyroidism.

\section{References}

Alvarez-Dolado, M., Iglesias, T., Rodríguez-Peña, A., Bernal, J., \& Muñoz, A. (1994). Expression of neurotrophins and the trk family of neurotrophin receptors in normal and hypothyroid rat brain. Molecular brain research, 27(2), 249-257.

Balazs, R., Brooksbank, B. W. L., Davison, A. N., Eayrs, J. T., \& Wilson, D. A. (1969). The effect of neonatal thyroidectomy on myelination in the rat brain. Brain research, 15(1), 219-232.

Ceni, C., Unsain, N., Zeinieh, M. P., \& Barker, P. A. (2014). Neurotrophins in the regulation of cellular survival and death. In Neurotrophic Factors (pp. 193-221). Springer Berlin Heidelberg.

Cooper, D. S. (2005). Antithyroid drugs. New England Journal of Medicine, 352(9), 905-917. 
Fauquier, T., Chatonnet, F., Picou, F., Richard, S., Fossat, N., Aguilera, N., ... \& Flamant, F. (2014). Purkinje cells and Bergmann glia are primary targets of the TR $\alpha 1$ thyroid hormone receptor during mouse cerebellum postnatal development. Development, 141(1), 166-175.

Gilbert, M. E., \& Lasley, S. M. (2013). Developmental thyroid hormone insufficiency and brain development: a role for brain-derived neurotrophic factor (BDNF)?. Neuroscience, 239, 253-270.

Gould, E., \& Butcher, L. L. (1989). Developing cholinergic basal forebrain neurons are sensitive to thyroid hormone. Journal of Neuroscience, 9(9), 3347-3358.

Gravel, C., \& Hawkes, R. (1990). Maturation of the corpus callosum of the rat: I. Influence of thyroid hormones on the topography of callosal projections. Journal of Comparative Neurology, 291(1), 128-146.

Gravel, C., Sasseville, R., \& Hawkes, R. (1990). Maturation of the corpus callosum of the rat: II. Influence of thyroid hormones on the number and maturation of axons. Journal of Comparative Neurology, 291(1), 147-161.

Lindholm, D., Castrén, E., Tsoulfas, P., Kolbeck, R., da P Berzaghi, M., Leingärtner, A., ... \& Tesarollo, L. (1993). Neurotrophin-3 induced by tri-iodothyronine in cerebellar granule cells promotes Purkinje cell differentiation. The Journal of Cell Biology, 122(2), 443-450.

Müller, J., \& Heuer, H. (2014). Expression pattern of thyroid hormone transporters in the postnatal mouse brain. Frontiers in endocrinology, 5.

Navarro, D., Alvarado, M., Morte, B., Berbel, D., Sesma, J., Pacheco, P., ... \& Berbel, P. (2013). Late maternal hypothyroidism alters the expression of Camk4 in neocortical subplate neurons: a comparison with Nurr1 labeling. Cerebral Cortex, 24(10), 2694-2706.

Perez-Castillo, A. N. A., Bernal, J., Ferreiro, B., \& Pans, T. (1985). The early ontogenesis of thyroid hormone receptor in the rat fetus. Endocrinology, 117(6), 2457-2461.

Ringstedt, T., Linnarsson, S., Wagner, J., Lendahl, U., Kokaia, Z., Arenas, E., ... \& Ibáñez, C. F. (1998). BDNF regulates reelin expression and Cajal-Retzius cell development in the cerebral cortex. Neuron, 21(2), 305-315.

Sinha, R. A., Pathak, A., Mohan, V., Bandyopadhyay, S., Rastogi, L., \& Godbole, M. M. (2008). Maternal thyroid hormone: a strong repressor of neuronal nitric oxide synthase in rat embryonic neocortex. Endocrinology, 149(9), 4396-4401.

Skaper, S. D. (2012). The neurotrophin family of neurotrophic factors: an overview. Neurotrophic Factors: Methods and Protocols, 1-12.

Wagner, M. S., Wajner, S. M., \& Maia, A. L. (2008). The role of thyroid hormone in testicular development and function. Journal of Endocrinology, 199(3), 351-365.

Wong, M. L., \& Medrano, J. F. (2005). Real-time PCR for mRN quantitation. Biotechniques, 39(1), 75-85.

Wood, W. M., Sarapura, V. D., Dowding, J. M., Woodmansee, W. W., Haakinson, D. J., Gordon, D. F., \& Ridgway, E. C. (2002). Early gene expression changes preceding thyroid hormone-induced involution of a thyrotrope tumor. Endocrinology, 143(2), 347-359.

\section{Copyrights}

Copyright for this article is retained by the author(s), with first publication rights granted to the journal.

This is an open-access article distributed under the terms and conditions of the Creative Commons Attribution license (http://creativecommons.org/licenses/by/4.0/). 